\title{
Effect of high-pressure torsion on microstructure, mechanical properties and corrosion resistance of cast pure Mg
}

\author{
Donya Ahmadkhaniha ${ }^{1}$, Yi Huang ${ }^{2,3}$, Matias Jaskari ${ }^{4}$, Antti Järvenpää ${ }^{4}$, Mahmoud Heydarzadeh Sohi ${ }^{5}$, \\ Caterina Zanella ${ }^{1}$, L. Pentti Karjalainen ${ }^{6}$, and Terence G. Langdon ${ }^{2, \star}$ (i) \\ ${ }^{1}$ Department of Material and Manufacturing, School of Engineering, Jönköping University, P.O. Box 1026, Gjuterigatan 5, \\ SE-551 11 Jönköping, Sweden \\ ${ }^{2}$ Materials Research Group, Department of Mechanical Engineering, University of Southampton, Southampton SO17 1BJ, UK \\ ${ }^{3}$ Department of Design and Engineering, Faculty of Science and Technology, Bournemouth University, Poole, Dorset BH12 5BB, UK \\ ${ }^{4}$ Kerttu Saalasti Institute, University of Oulu, Pajatie 5, 85500 Nivala, Finland \\ ${ }^{5}$ School of Metallurgy and Materials, College of Engineering, University of Tehran, PO Box 1155-4563, Tehran, Iran \\ ${ }^{6}$ Centre for Advanced Steels Research, University of Oulu, PO Box 4200, 90014 Oulu, Finland
}

Received: 9 May 2018

Accepted: 4 August 2018

Published online:

13 August 2018

(C) The Author(s) 2018

\begin{abstract}
High-pressure torsion (HPT) processing was applied to cast pure magnesium, and the effects of the deformation on the microstructure, hardness, tensile properties and corrosion resistance were evaluated. The microstructures of the processed samples were examined by electron backscatter diffraction, and the mechanical properties were determined by Vickers hardness and tensile testing. The corrosion resistance was studied using electrochemical impedance spectroscopy in a $3.5 \% \mathrm{NaCl}$ solution. The results show that HPT processing effectively refines the grain size of $\mathrm{Mg}$ from millimeters in the cast structure to a few micrometers after processing and also creates a basal texture on the surface. It was found that one or five turns of HPT produced no significant difference in the grain size of the processed $\mathrm{Mg}$ and the hardness was a maximum after one turn due to recovery in some grains. Measurements showed that the yield strength of the cast $\mathrm{Mg}$ increased by about seven times whereas the corrosion resistance was not significantly affected by the HPT processing.
\end{abstract}

\section{Introduction}

In recent years, magnesium and its alloys have emerged as candidate biodegradable materials in cardiovascular and musculoskeletal applications
[1, 2]. However, the promising biodegradable applications of $\mathrm{Mg}$ and its alloys depend on the ability to control their mechanical strength and the corrosion rate in body fluids. Therefore, much research has focused on the special processing of $\mathrm{Mg}$ and its alloys

Address correspondence to E-mail: langdon@soton.ac.uk 
in order to modify the properties and thereby commercialize biodegradable $\mathrm{Mg}$ alloys. Several methods have been proposed to protect $\mathrm{Mg}$ against corrosion, such as Mg purification [3], the use of coatings [4-6] and alloying with other elements [7-9]. Since $\mathrm{Mg}$ in the as-cast condition suffers from both low mechanical strength and poor corrosion resistance, it is challenging in practice to find a processing route which can enhance both properties simultaneously.

It is known that mechanical processing can increase the mechanical strength via grain refinement and modify the texture of materials to thereby have an impact on the corrosion behavior. Furthermore, different techniques have been applied, such as extrusion [10], surface mechanical attrition treatment and equal-channel angular pressing (ECAP) [11], to improve the strength and corrosion resistance through the refined microstructure.

Although these processing procedures are effective for achieving significant grain refinement, several experiments have suggested that the use of highpressure torsion (HPT) may have some benefits because of the ability to refine the microstructure more effectively and also to process alloys with low deformability at room temperature [12-14]. Processing by HPT is a severe plastic deformation (SPD) technique that applies high pressure and shear strain to a thin disk or ring held between two rotating anvils [15]. In the present investigation, HPT processing was applied to cast pure $\mathrm{Mg}$ disk samples and mechanical testing and the corrosion performance were evaluated both before and after the HPT. By choosing pure $\mathrm{Mg}$ as the workpiece, it was possible to evaluate the effect of microstructure on the corrosion resistance without interference from the distribution and size of any intermetallic and secondary phases.

\section{Experimental material and procedures}

Commercially pure as-cast $\mathrm{Mg}$ disks, having diameters of $10 \mathrm{~mm}$ and thicknesses of $0.8 \mathrm{~mm}$, were processed by HPT by compressing and then deforming between two anvils under an applied pressure of 6.0 GPa at room temperature to totals of either one or five complete turns. This processing was conducted under quasi-constrained conditions in which there is a small outflow of material around the periphery of the disk during the processing operation [16, 17]. Care was taken to ensure there was no slippage during HPT by placing marker lines on the upper and lower surfaces of each disk prior to processing [18].

The microstructures of the samples, both at the top surfaces and at the cross sections, were characterized using a scanning electron microscope (SEM; Zeiss Ultra Plus) equipped with an electron backscatter diffraction (EBSD) device (Zeiss-Oxford Instruments, $15-20 \mathrm{kV}$, aperture $120 \mu \mathrm{m}$, working distance 10 $12 \mathrm{~mm}$, step size typically $<0.6 \mu \mathrm{m}$; HKL Channel 5 software). The as-cast Mg and HPT-processed samples were cold mounted and a very gentle grinding was used before the polishing procedure to avoid introducing any deformation layer. The incomplete pole figures $(0001,10 \overline{1} 0,11 \overline{2} 0)$ were used to determine the texture. Areas having a minimum size of $100 \times 100 \mu \mathrm{m}^{2}$ were scanned in order to include an adequate number of grains in the texture analyses for all samples except in the initial cast structure. The grain size was measured from the EBSD data using the equivalent circular diameter in the HKL Channel5 software.

Microhardness measurements were carried out on the surfaces of samples along randomly selected diameters using a nano-test Vantage apparatus with a Vickers indenter (load $100 \mathrm{mN}$ ) and a dwell time of 10 s. A Zwick Z030 testing machine was used to investigate the tensile behavior at room temperature of miniature tensile samples cut from the HPT disks. Two tensile samples were prepared from off-center positions for the initial as-cast $\mathrm{Mg}$ and the HPTprocessed disks as shown in Fig. 1 [19], and these

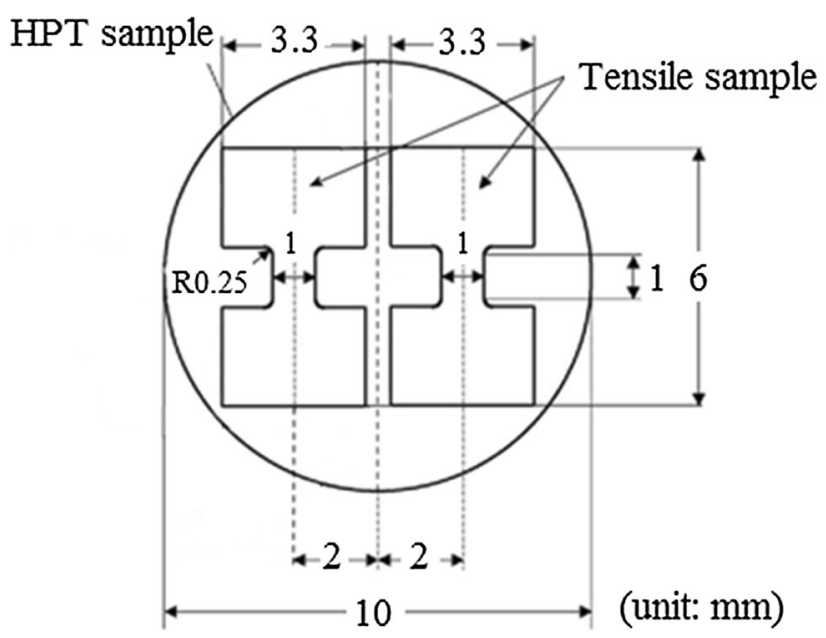

Figure 1 Dimensions of mini-tensile samples cut from HPT disks [19]. 
samples were tested using initial strain rates of $1.0 \times 10^{-3} \mathrm{~s}^{-1}$.

A horizontal three-electrode electrochemical cell, with platinum as a counter-electrode, $\mathrm{Ag} / \mathrm{AgCl}$ ( $3 \mathrm{M}$ $\mathrm{KCl}, 0.21$ vs. SHE/V) as a reference electrode and $\mathrm{Mg}$ sample as a working electrode, was chosen to evaluate the corrosion resistance in a $3.5 \% \mathrm{NaCl}$ solution. The sample surfaces were ground with $\mathrm{SiC}$ abrasive papers up to 1000 grade before initiating the electrochemical testing. Electrochemical impedance spectroscopy (EIS) was carried out at an open-circuit potential (OCP) with an initial delay of $10 \mathrm{~min}$ by applying a sinusoidal wave of $10 \mathrm{mV}$ amplitude over a frequency range from $10 \mathrm{mHz}$ to $100 \mathrm{kHz}$. A ZSimpwin commercial software was used to fit the experimental data.

\section{Experimental results}

\section{Microstructure and texture}

The microstructures of the top surfaces in the cast and HPT-processed Mg samples after one and five turns are shown in the EBSD overlapped inverse pole figure (IPF) and grain boundary maps in Fig. 2 where the colors denote different grain orientations as depicted in the upper unit triangle. It can be seen that the cast $\mathrm{Mg}$ in Fig. 2a has a very coarse grain structure of a few millimeters with some twins whereas the grain sizes in the HPT-processed samples were refined significantly to $\sim 1.6-4.0 \mu \mathrm{m}$ in Fig. $2 \mathrm{~b}-\mathrm{g}$ for the centers, halfway positions and edges of the disks, respectively. A comprehensive summary is given in Table 1 of the grain sizes at the top surfaces for these three positions for both a combination of low-angle grain boundaries (LAGBs having misorientations below $15^{\circ}$ ) and high-angle grain boundaries (HAGBs with misorientations at and above $15^{\circ}$ ) and for the HAGBs only.

Figure $2 \mathrm{~b}-\mathrm{g}$ relates to the surface microstructures of the HPT-processed disks at these different radial locations within the circular samples and inspection suggests that they exhibit typical bimodal grain size distributions. The microstructures of both samples at the center after one and five turns in Fig. $2 b$, e are composed of a relatively large fraction of coarser grains mixed together with a small fraction of fine grains. By contrast, the fractions and sizes of the coarser grains are reduced at greater distances from the center. These results demonstrate, therefore, that the grain structure tends to become more uniform from the center to the edge along the radial direction and this is reasonable considering the increase in strain with increasing distance from the center.

According to Fig. 2, the HPT processing refined the grain structure and resulted in much refined equiaxed grains. It can be seen that, in addition to grains of several micrometers in size, there are much smaller grains of a few micrometers. This is most evident after one turn and at the center and therefore after the smallest strain (Fig. 2b) where very small grains are located in groups which are evidently within prior grains and they are not formed as necklace-like structures along the original grain boundaries of the large grains. None of these grain groups are red so that they are without the basal texture component. All very small grains have the same orientation, so that the grain boundaries between them are LAGBs and they correspond to subgrain boundaries. It is concluded that these grains are not recrystallized but they are dynamically recovered. Because the groups are absent after higher strains (from Fig. 2c onwards), although smaller and larger grains remain evident in the images, it seems that continuous dynamic recrystallization takes place in these grain areas at larger strains where the large grains are a consequence of discontinuous recrystallization.

A bimodal grain structure was found that was similar to that reported after HPT of $\mathrm{Mg}$ in earlier reports $[15,20]$. For example, there was a bimodal microstructure including large recrystallized grains, free of dislocations, in the steady-state condition with an average grain size of about $1 \mu \mathrm{m}$ [15] and there is another report of equiaxed grains with a size of about 1-5 $\mu \mathrm{m}$ [20]. Because the latter grain size increased with increased applied pressure, it was concluded that the grains are formed by both discontinuous static and dynamic recrystallization mechanisms. Thus, after 5 turns and 6 GPa pressure two different types of regions were reported, with "deformed regions" having ultrafine grains and a high density of dislocations and "recrystallized regions" with substantially larger grains $(1-5 \mu \mathrm{m})$ and almost free of dislocations [21]. Thus, the bimodal grain structure observed in the present investigation has similarities to several earlier reports.

The sample processed by five turns also demonstrated a similar variation in the grain structure as in 

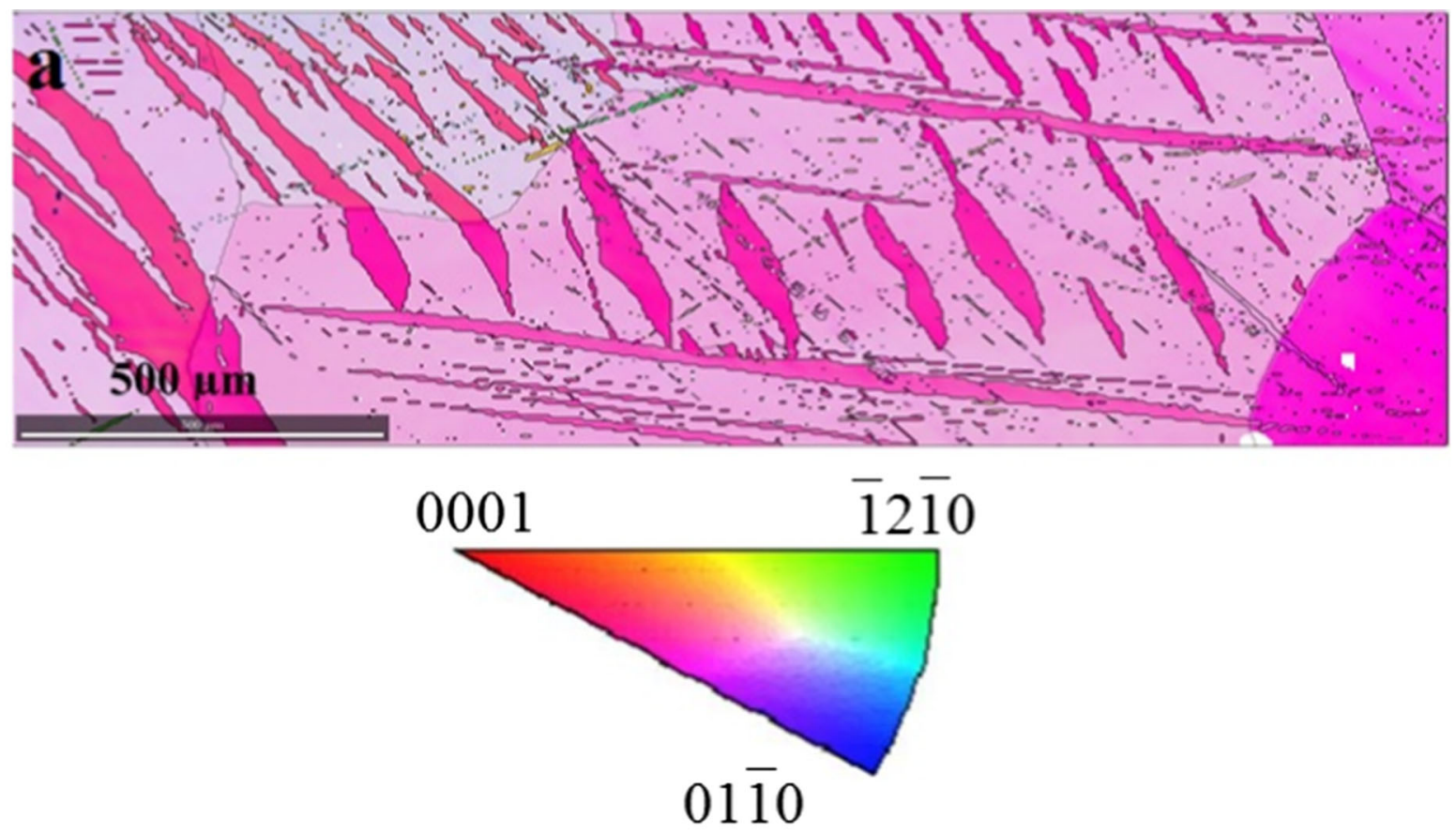

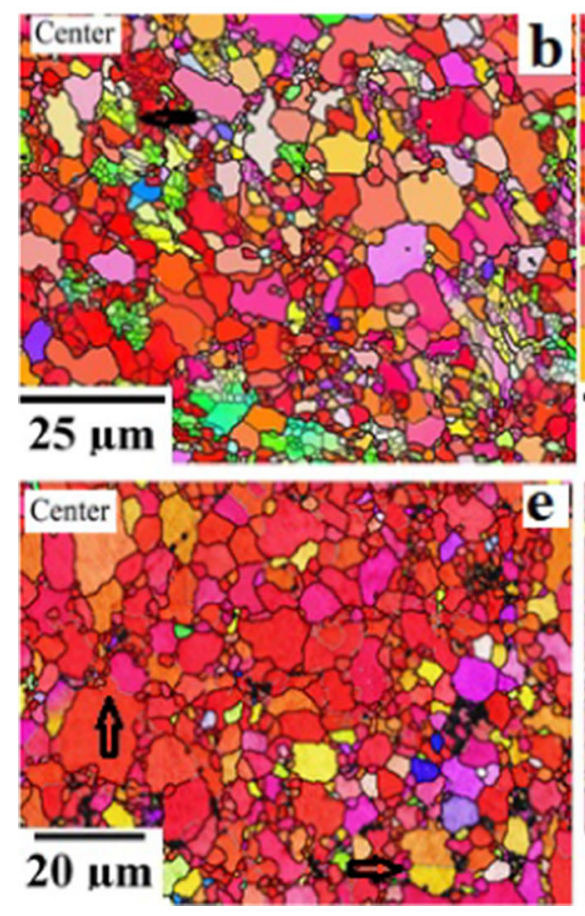

Figure 2 EBSD images of the surface in a cast Mg and in HPTprocessed $\mathrm{Mg}$ with $\mathbf{b}-\mathbf{d} 1$ and $\mathbf{e}-\mathbf{g} 5$ turns; the positions are $\mathbf{b}$, e center, $\mathbf{c}, \mathbf{f}$ halfway and $\mathbf{d}, \mathbf{g}$ edge of the samples; high-angle

the one-turn sample. Furthermore, the grain size showed no significant change with increasing numbers of turns as documented in Table 1 except only at the disk center where there is no torsional straining grain boundaries are black and low-angle boundaries are gray in color with black spots denoting non-indexed pixels.

and consequently there was only a high compressive load.

In the EBSD images in Fig. 2, it is readily apparent that most of the grains are red in color. This means 
Table 1 Average grain size values $(\mu \mathrm{m})$ with the standard deviation at different locations in the HPT-processed $\mathrm{Mg}$

\begin{tabular}{llllll}
\hline Location & \multicolumn{2}{l}{$N=1$} & & \multicolumn{2}{l}{$N=5$} \\
\cline { 2 - 3 } \cline { 5 - 6 } & LAGB + HAGB & HAGB & & LAGB + HAGB & HAGB \\
\hline Center & $3.8 \pm 2.6$ & $4.1 \pm 4.6$ & & $2.0 \pm 1.7$ & $2.2 \pm 1.9$ \\
Halfway & $1.8 \pm 1.5$ & $2.4 \pm 2$ & & $2.0 \pm 1.3$ & $2.2 \pm 1.6$ \\
Edge & $1.6 \pm 0.4$ & $1.6 \pm 0.2$ & & $1.6 \pm 1.2$ & $1.8 \pm 1.4$ \\
\hline
\end{tabular}

$N$ number of turns, $L A G B$ low-angle grain boundary (misorientation $<15^{\circ}$ ), $H A G B$ high-angle grain boundary (misorientation $>15^{\circ}$ ) that the $\{0001\}$ planes are parallel to the disk surface and this preferred orientation is essentially maintained over the entire surface. Figure 3 displays the pole figures of the HPT-processed $\mathrm{Mg}$ at different locations after $(\mathrm{a}-\mathrm{c}) 1$ and $(\mathrm{d}-\mathrm{f}) 5$ turns. Thus, the pole figures after one turn at the center of the sample demonstrate a $\{0001\}<10 \overline{1} 0>$ basal texture with an increasing intensity with increasing strain toward the edge of the sample. The ODF plots in Fig. 4 also confirm the texture evolution on the surface through the radius of the sample and by increasing to five turns of HPT a homogenous $\{0001\}$ basal texture exists over the whole sample surface as is evident in Fig. 3. Since the as-cast $\mathrm{Mg}$ had coarse grains, and in the cross sections only two or three grains were visible, it was not possible to determine the texture.

In order to check the homogeneity of the grain structure through the cross sections of the HPT-processed disks, the microstructure over the whole thickness after one turn is presented in Fig. 5 in three radial locations. The orientation of the grains is viewed in two directions, the direction perpendicular to the disk surface (Fig. $5 \mathrm{a}-\mathrm{c}$ ) as well as in a direction parallel to the surface (Fig. $5 \mathrm{~d}-\mathrm{f}$ ). The first images show red grains so that there is a strong basal texture through the disk parallel to the surface. The final three images (Fig. $5 \mathrm{~d}-\mathrm{f}$ ) show bluish and greenish colors so that most of the grains have orientations close to $(01 \overline{1} 0)$ and (1210) when looking toward the cross section of one-half of the disk. The microstructure through the thickness is not entirely homogeneous after one turn in the center region and there are a few flattened (about $100 \mu \mathrm{m}$ long) grains containing LAGBs which indicate the occurrence of recovery in this region (see Fig. 5a, the encircled larger grains). Very small recovered grains of a few micrometers in size were also observed at the surface layer (in Fig. 2b) but due to a much lower resolution in Fig. 5a these grains cannot be resolved. It appears that dynamic recrystallization can occur in most grains already during one turn but also there are areas of dynamic recovery. Inhomogeneities through the cross sections of HPT-processed disks were also reported in some other investigations [22-24]. It is noted that in the halfway and edge regions in Fig. 5b, $c$ the grains appear to be more uniform in size and recrystallized, which is similar to the conclusions from Fig. 2c, d.

Figure 6 presents pictorial displays of the distributions of the area fractions of different grain sizes at the center and edge for both ( $a$ and $b$ ) one and (c and d) five turns. After one turn at the center in Fig. 6a, there is a distinct difference between the top and bottom layer, with the former having a higher fraction of fine $(<10 \mu \mathrm{m})$ grains and the latter having more numerous larger $(>30 \mu \mathrm{m})$ grains. This difference is not so pronounced at the edge in Fig. $6 \mathrm{~b}$ and after five turns the grain sizes became more homogeneous in Fig. $6 c-d$ and the grain size distributions through the thickness after 5 turns are similar in the top and bottom of the sample.

\section{Microhardness}

The microhardness of the samples was measured in order to estimate the changes in the microstructure and strength attributed to the HPT processing. Figure 7 shows the variation in Vickers microhardness as a function of distance from the center of the disk samples in the as-cast material and after 1 and 5 turns. The initial hardness of the as-cast $\mathrm{Mg}$ was relatively high, $41 \mathrm{Hv}_{0.01}$. The results show that the hardness increases clearly by one turn of HPT processing to about $60 \mathrm{Hv}_{0.01}$. However, increasing the turns to 5 slightly decreases the hardness. Thus, the hardness variation is irregular and any sign of a peak or any trend by distance from the centers of the disks is not generally apparent from these data. These results are in agreement with other observations 
Figure 3 Pole figures of the surface of the HPT-processed samples at different locations: a-c 1 turn, d-f 5 turns with positions of $\mathbf{a}, \mathbf{d}$ center, $\mathbf{b}$, e halfway and $\mathbf{c}, \mathbf{f}$ edge.
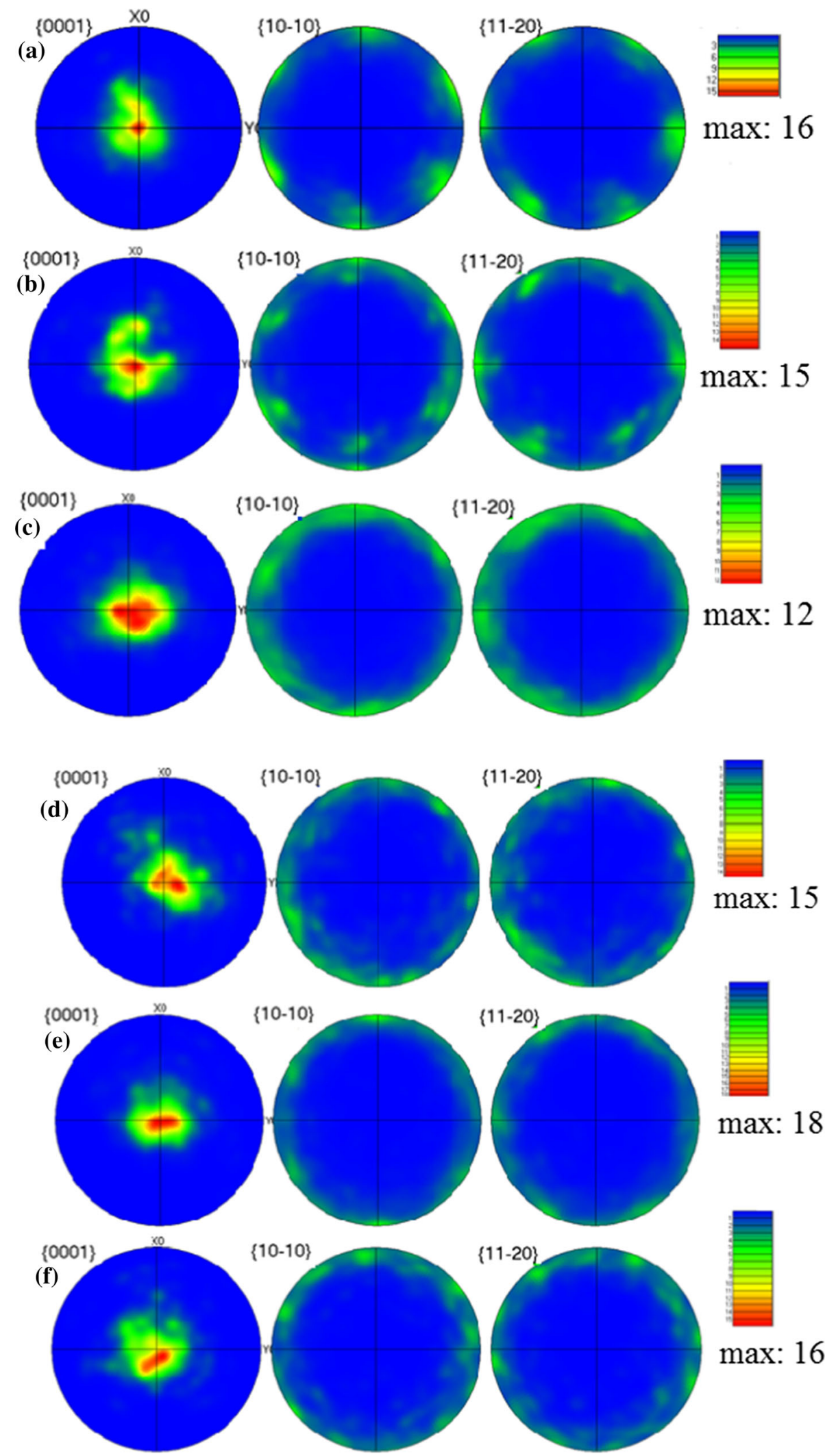


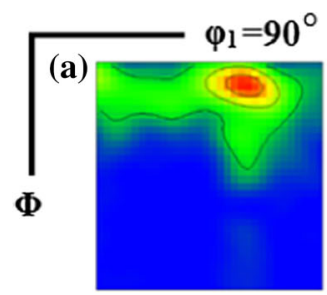

$\varphi_{2}=0^{\circ}$

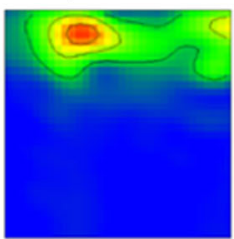

$\varphi_{2}=30^{\circ}$

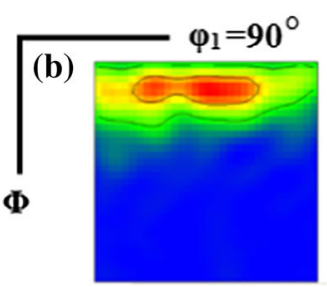

$\varphi_{2}=0^{\circ}$

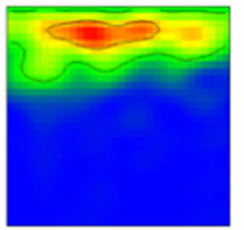

$\varphi_{2}=30^{\circ}$

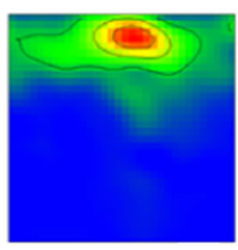

$\varphi_{2}=10^{\circ}$

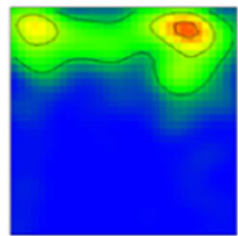

$\varphi_{2}=50^{\circ}$

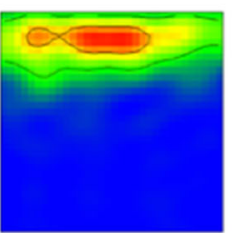

$\varphi_{2}=10^{\circ}$

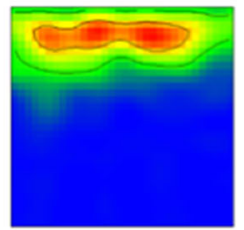

$\varphi_{2}=\mathbf{5 0}{ }^{\circ}$

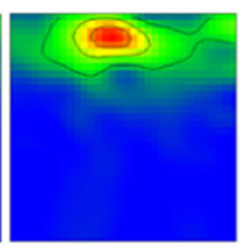

$\varphi_{2}=20^{\circ}$

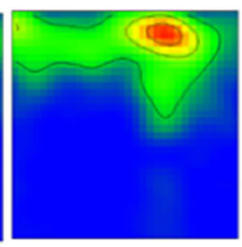

$\varphi_{2}=60^{\circ}$

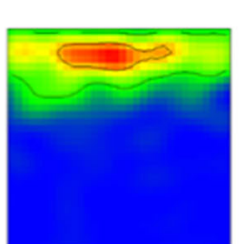

$\varphi_{2}=20^{\circ}$

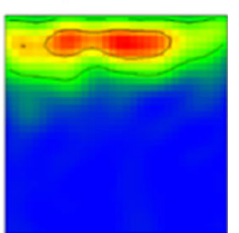

$\varphi_{2}=60^{\circ}$
Figure 4 ODF plots for surfaces of an HPT sample with 1 turn at a center and $\mathbf{b}$ edge.

$[15,25]$. For example, there is a report that even after less than one turn there was an increase in hardness with respect to the distance from the center but at higher deformations the opposite occurred due to dynamic softening.

In practice, the hardness is affected by three separate factors: the finer grain size, the texture of the HPT samples and the higher dislocation density which is an inherent feature of the SPD-processed microstructure. In this study, the microhardness of HPT samples did not change by increasing the distance from the center although the grain size was slightly reduced. The basal texture is quite similar over the total surface as shown in Fig. 2, 3 and 4. Therefore, the dislocation density and thus the extent of recovery must vary with strain and have the main impact on the microhardness values. After one turn at the center, there are numerous subgrains and it is concluded that there is a higher dislocation density in an incompletely recrystallized structure which accounts for the higher hardness in this stage.

The grain boundary misorientation distributions displayed in Fig. 8 also confirm the existence of higher numbers of LAGBs, and therefore of recovered grains, after 1 turn compared with 5 turns, where it was shown earlier that the two main peaks, appearing at about $27^{\circ}$ and $88^{\circ}$, correspond to the existence of doubled and tensile twins [26]. The fraction of LAGBs varies along the radial directions due to the different strain concentrations and in practice the fraction is higher at the center than in the edge region. Thus, after 5 turns a fully recrystallized structure was achieved with a lower hardness instead of a partly recovered structure.

It has been noted that a softening behavior tends to occur in pure metals when the homologous temperature is larger than $\sim 0.3$ [27] and in the present investigation the homologous temperature was $~$ 0.32. It was observed by transmission electron microscopy that a replacement of the "deformed regions" in HPT Mg by dislocation-free recrystallized grains led to a softening [21] and it was suggested that, due to the faster defect recovery in $\mathrm{Mg}$ compared to metals such as $\mathrm{Al}, \mathrm{Cu}$ and $\mathrm{Ag}$, a saturation in hardening may occur in $\mathrm{Mg}$ at lower strains than in those other metals [25].

It was also noted earlier that additional HPT processing after $1 / 8$ turn produced no significant increase in the microhardness [25] and this hardening at very small strains is probably due to the hexagonal closepacked (hcp) structure which provides basal slip and only two independent slip systems which are easily activated at room temperature. In order to fulfill the von Mises criterion, twinning and/or non-basal slip is also required at the onset of the HPT deformation [28].

\section{Tensile properties}

Processing by SPD procedures is used conventionally to improve the strength properties of bulk solids. Accordingly, tensile testing was conducted both before and after HPT processing and representative engineering stress-strain curves for the cast and HPT-processed miniature samples are plotted in Fig. 9. These curves show that the yield and ultimate tensile strengths are markedly increased by HPT processing as listed in Table 2, but conversely, and as anticipated from the paradox of strength and 

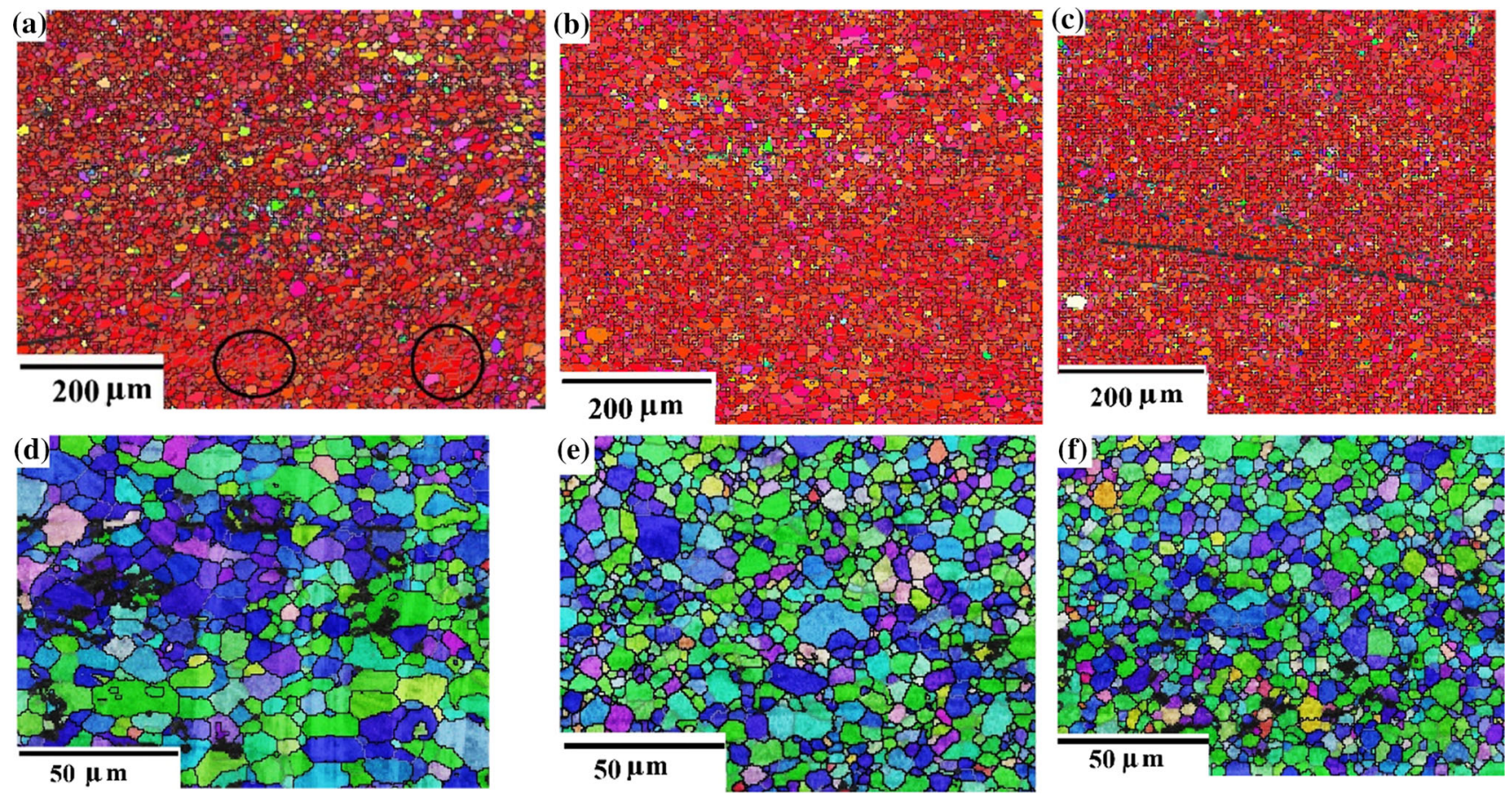

Figure 5 EBSD images over the cross sections of an HPTprocessed $\mathrm{Mg}$ sample after one turn. a-c Images from the top to the bottom, the view direction toward the upper surface. $\mathbf{d}-\mathbf{f}$ High magnification images, the view direction toward the normal of the

ductility [29], the overall elongations are reduced through HPT processing. The concave tensile behavior of the cast $\mathrm{Mg}$ was explained previously [26]. Apart from the grain refinement and the dislocation density, texture strengthening also contributes to strength of $\mathrm{Mg}$. In practice, texture strengthening is generally caused by deformation along the forming direction which limits basal slip and is beneficial for the activation of non-basal slip and thereby results in an increasing yield strength. It should also be considered that the low stacking fault energy on the basal plane $\left(36 \mathrm{~mJ} \mathrm{~m}^{-2}\right)$ may reduce the dislocation slip and cause strain hardening [30].

\section{Corrosion resistance}

Corrosion resistance is one of the most important properties for biomedical applications since corrosion products may give some cytotoxicity effects and low corrosion resistance can cause a significant reduction in mechanical strength. Therefore, in this research the corrosion resistance of the samples was examined to determine whether HPT retards or facilitates the corrosion of $\mathrm{Mg}$. cross-sectional surface. a, d Center, b, e halfway, c, f edge. Highangle grain boundaries are black and low-angle boundaries gray in color. Two large recovered grains are encircled in $\mathbf{a}$.

Figure 10 shows the Nyquist impedance plots for the cast and HPT-processed $\mathrm{Mg}$ when using $\mathrm{NaCl}$ solution. It can be seen that the plots for all samples include one capacitive loop and one inductive loop at low frequency. The capacitive loop has been assigned to charge transfer and film effects and the low-frequency inductive loop is related to the relaxation of adsorbed species such as $\mathrm{Mg}^{+}$and non-stationary conditions [31]. The same shapes of the Nyquist plots, as well as the same diameters of the capacitive loops for all samples, suggest a similar corrosion mechanism and equal corrosion rates. Two earlier studies determined two time constants for $\mathrm{Mg}$ and its alloys immersed in $\mathrm{NaCl}$ [31, 32] where a reduction in the corrosion resistance of pure $\mathrm{Mg}$ was observed after processing by ECAP. Figure 11 shows the equivalent circuit that was used to fit the impedance data by ZSimpwin software and the results are listed in Table 3 where $R_{\mathrm{s}}$ is the electrolyte resistance between the working and reference electrode, $C_{\mathrm{dl}}$ is the electrochemical double-layer capacitance at the substrate/electrolyte interface and $R_{\mathrm{CT}}$ is the charge transfer resistance. For a best fit with the experimental data, the inductive part was omitted from the equivalent circuit and the fitting was carried out between 1 and $100 \mathrm{kHz}$. 

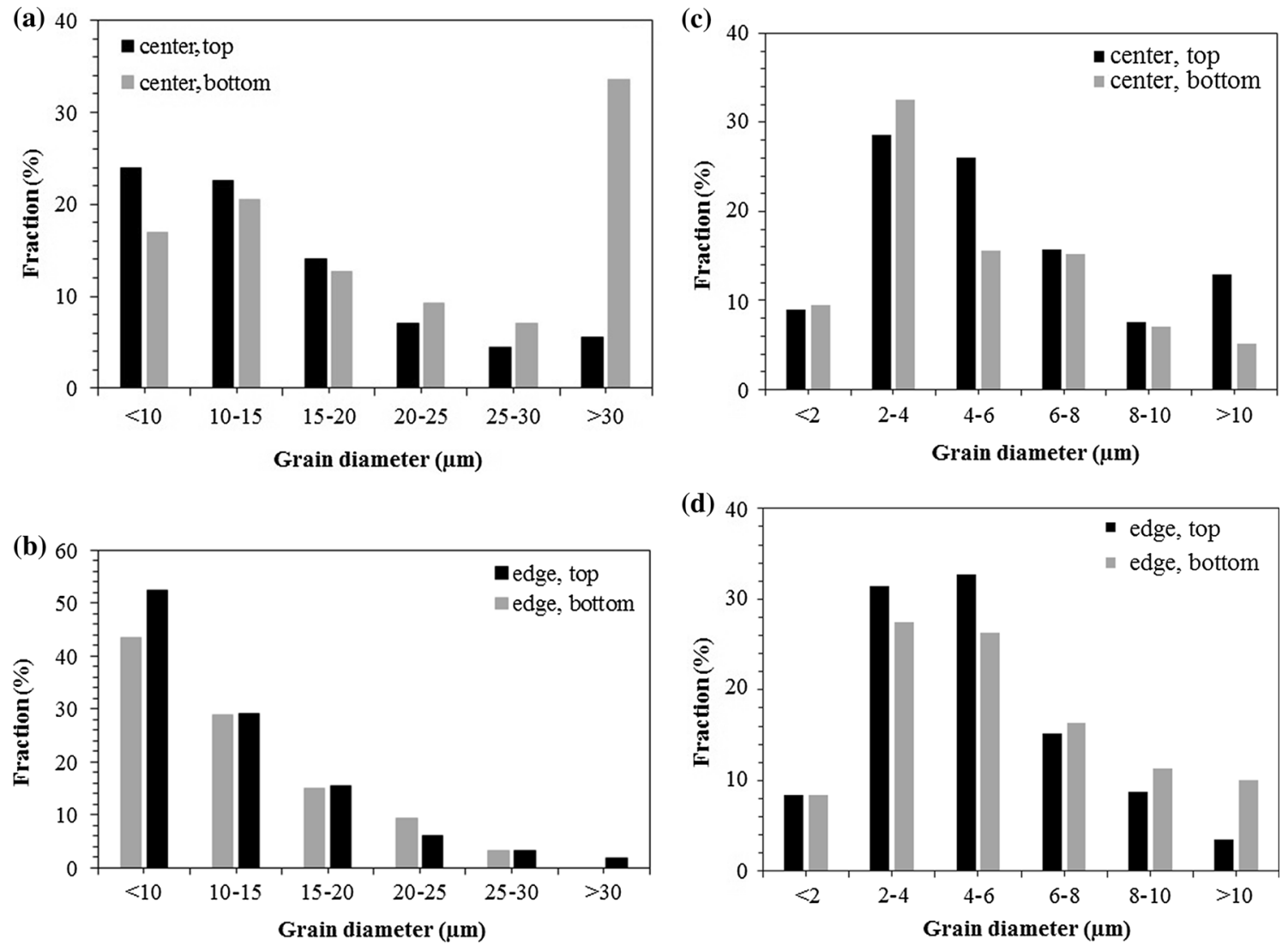

Figure 6 Grain size distributions in cross sections of HPT samples: $\mathbf{a}, \mathbf{b} 1$ turn and $\mathbf{c}, \mathbf{d} 5$ turns with positions of $\mathbf{a}, \mathbf{c}$ center, $\mathbf{b}, \mathbf{d}$ edge for top and bottom measurements.

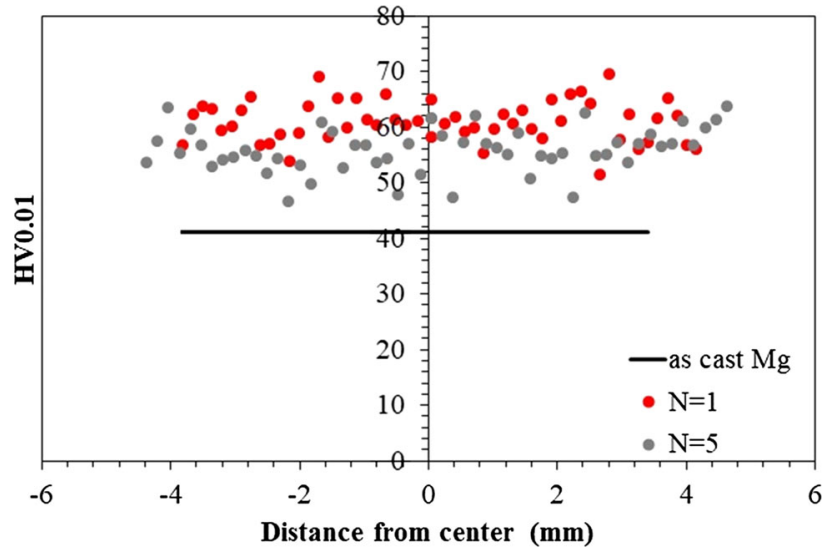

Figure 7 Microhardness values of the as-cast and HPT-processed samples versus the distance from the center of the samples.

\section{Discussion}

The results from this investigation are generally consistent with expectations. Processing by HPT produces a very significant grain refinement in the cast pure $\mathrm{Mg}$ with a grain size reduction at the edge

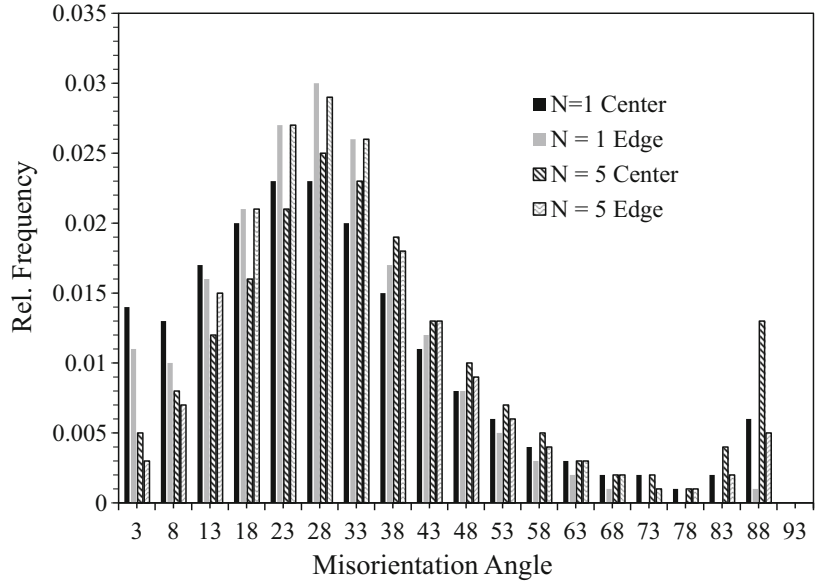

Figure 8 Misorientation angles in HPT samples at center and edge after 1 and 5 turns.

of the disk from an initial value of several millimeters to processed values of $\sim 1.6 \mu \mathrm{m}$ after both 1 and 5 turns. Generally, processing of pure $\mathrm{Mg}$ is difficult using SPD techniques. For example, the processing of pure $\mathrm{Mg}$ by the alternative procedure of ECAP at 


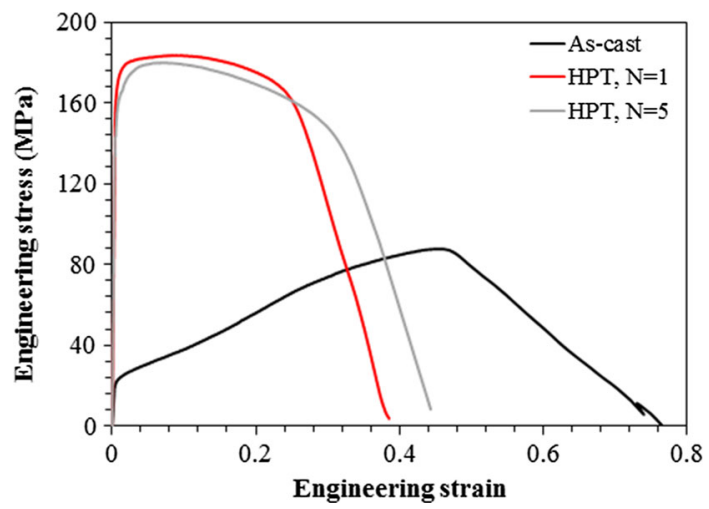

Figure 9 Engineering stress-strain curves of the cast and HPTprocessed samples at room temperature.

$673 \mathrm{~K}$ led to a reduction in grain size from $\sim 400 \mu \mathrm{m}$ to a grain size larger than $100 \mu \mathrm{m}$ after processing through 2 passes [33]. This difficulty arose because of the lack of slip systems in the hcp structure and the potential for introducing cracking or large-scale segmentation $[34,35]$. The problem was at least partially alleviated when using ECAP by introducing an initial extrusion step and then processing at an elevated temperature [36]. In the present investigation, the $\mathrm{HPT}$ was conducted directly using the cast $\mathrm{Mg}$ without any extrusion and the processing was performed at room temperature where the high hydrostatic pressure inherent in HPT permitted successful processing of the pure metal without the introduction of any cracking. Using room temperature for the processing operation is advantageous because it avoids the occurrence of significant grain growth which will occur when conducting the HPT at elevated temperatures [12].

The hardness behavior in these experiments is unusual because in many materials, including $\mathrm{Mg}$ alloys [37], the hardness increases with increasing numbers of turns and then saturates after about 5 to 10 turns $[27,38,39]$. In the present experiments, the hardness increased from the cast condition but it was slightly higher after 1 turn than after 5 turns due to the advent of recrystallization.

According to the present data, there is no significant improvement in the corrosion resistance by

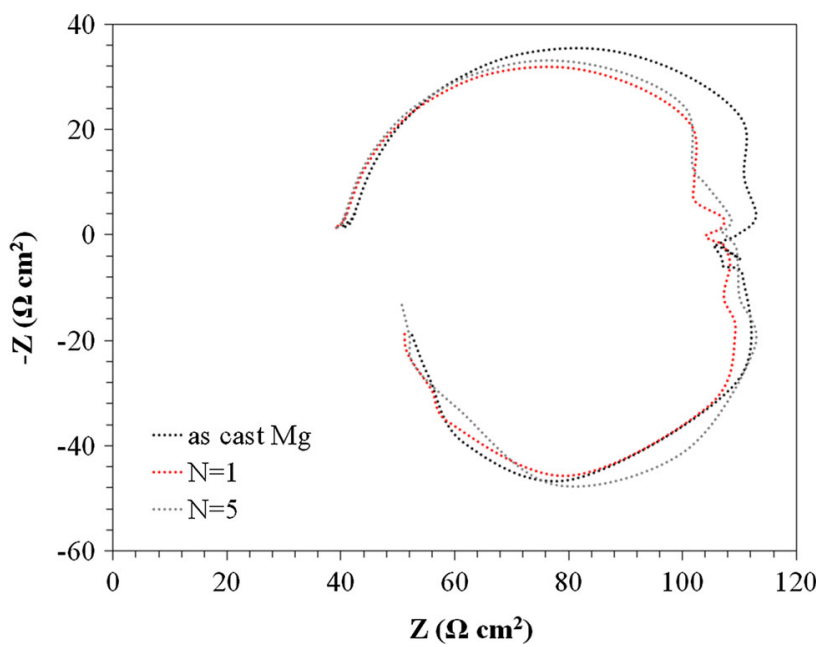

Figure 10 Nyquist plots of the cast and HPT-processed $\mathrm{Mg}$ in an $\mathrm{NaCl}$ solution.

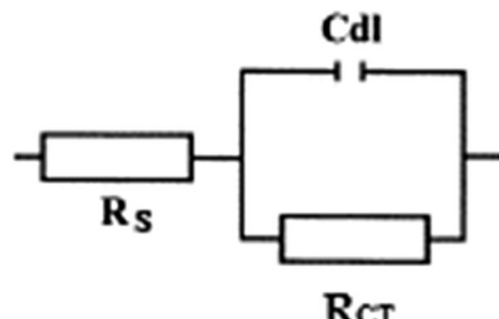

Figure 11 Equivalent circuits used for fitting the impedance data.

Table 3 Fitting data related to the impedance measurements for as-cast and HPT-processed $\mathrm{Mg}$

\begin{tabular}{llll}
\hline Parameters & As-cast $\mathrm{Mg}$ & $\mathrm{N}=1$ & $\mathrm{~N}=5$ \\
\hline$R_{\mathrm{s}}\left(\Omega \mathrm{cm}^{2}\right)$ & 42 & 40 & 40 \\
$C_{\mathrm{dl}}\left(\mu \mathrm{F} \mathrm{cm}{ }^{-2}\right)$ & $4.1 \times 10^{-5}$ & $4.7 \times 10^{-5}$ & $5.3 \times 10^{-5}$ \\
$R_{\mathrm{CT}}\left(\Omega \mathrm{cm}^{2}\right)$ & 71 & 65 & 67 \\
\hline
\end{tabular}

applying the HPT processing to pure cast $\mathrm{Mg}$. Nevertheless, it was shown earlier that HPT-treated samples possessed a lower biodegradation rate with respect to the as-cast $\mathrm{Mg}$ alloy due to the relieving of internal stresses [40]. In the case of $\mathrm{Mg}$, the oxide layer is crystalline in nature and the microstructure is discontinuous between the oxide layer and the matrix

Table 2 Tensile properties of as-cast and HPT-processed $\mathrm{Mg}$

\begin{tabular}{lccc}
\hline Sample & Yield strength (MPa) & Tensile strength (MPa) & Elongation (\%) \\
\hline As-cast & $18 \pm 0.4$ & $83 \pm 1.2$ & 46 \\
$N=1$ & $150 \pm 9.2$ & $181 \pm 0.7$ & 30 \\
$N=5$ & $142 \pm 5.6$ & $180 \pm 7.1$ & 38 \\
\hline
\end{tabular}


leading to a high compressive stress within this layer. It was noted also that the increase in grain boundary density can reduce the mismatch and disorder between the Mg surface and the oxide layer [32] and, in addition, it has been confirmed that a surface with an (0001) plane has improved corrosion resistance by comparison with (1010) and (1120) planes even when the grain size remains the same [41]. An earlier study on pure $\mathrm{Mg}$ suggested that processing by ECAP or HPT leads to an overall change in the macroscopic corrosion behavior so that, whereas pure $\mathrm{Mg}$ generally exhibits a localized corrosion in the as-cast condition, processing by HPT produces a reasonably homogeneous corrosion surface [40].

The apparent general lack of any major improvement in the corrosion behavior in this research is consistent with results on some other materials such as commercial purity $\mathrm{Ti}$ processed by HPT [42]. Nevertheless, based on the results in Table 3, it appears that other metallurgical and structural factors associated with HPT processing, such as the presence of residual stresses or the introduction of high dislocation densities, may have a larger influence on the corrosion behavior than either the grain size or the texture. Accordingly, it is recommended that additional experiments are conducted to more fully characterize the corrosion resistance of pure $\mathrm{Mg}$ after processing by HPT.

\section{Summary and conclusions}

1. Cast pure Mg disks were processed by HPT at room temperature using 1 or 5 turns. The results show that the processing refines the grain size from a few millimeters to a few micrometers and also creates a strong dominant basal texture through the disk.

2. Measurements showed that the grain size was effectively refined and the basal texture was intense even after processing through only 1 turn. Nevertheless, the microstructure became more homogeneous throughout the disks by increasing the HPT processing to 5 turns. The refined grain structure also exhibited recovered grains with low-angle grain boundaries at the surface layer and a few large recovered grains at the bottom layer of the disk in the center region after one turn.
3. The highly refined grain size, substructure within a few grains and the basal texture resulted in a slightly higher microhardness after 1 turn than after 5 turns. The yield stress was also enhanced to about seven times in comparison with the cast $\mathrm{Mg}$.

4. The results suggest that the corrosion resistance was not significantly improved by using HPT processing but more experiments are needed to more fully characterize the corrosion resistance.

\section{Acknowledgement}

YH and TGL were supported in part by the European Research Council under Grant Agreement No. 267464-SPDMETALS.

Open Access This article is distributed under the terms of the Creative Commons Attribution 4.0 International License (http://creativecommons.org/ licenses/by/4.0/), which permits unrestricted use, distribution, and reproduction in any medium, provided you give appropriate credit to the original author(s) and the source, provide a link to the Creative Commons license, and indicate if changes were made.

\section{References}

[1] Staiger MP, Pietak AM, Huadmai J, Dias G (2006) Magnesium and its alloys as orthopedic biomaterials: a review. Biomaterials 27:1728-1734

[2] Witte F (2010) The history of biodegradable magnesium implants: a review. Acta Biomater 6:1680-1692

[3] Song G (2007) Control of biodegradation of biocompatable magnesium alloys. Corros Sci 49:1696-1701

[4] Li L, Gao J, Wang Y (2004) Evaluation of cyto-toxicity and corrosion behavior of alkali-heat-treated magnesium in simulated body fluid. Surf Coat Technol 185:92-98

[5] Wang Y, Wei M, Gao J (2009) Improve corrosion resistance of magnesium in simulated body fluid by dicalcium phosphate dihydrate coating. Mater Sci Eng C 29:1311-1316

[6] Hornberger H, Virtanen S, Boccaccini AR (2012) Biomedical coatings on magnesium alloys - a review. Acta Biomater 8:2442-2455

[7] Hänzi AC, Gerber I, Schinhammer M, Löffler JF, Uggowitzer PJ (2010) On the in vitro and in vivo degradation 
performance and biological response of new biodegradable Mg-Y-Zn alloys. Acta Biomater 6:1824-1833

[8] Zong Y, Yuan G, Zhang X, Mao L, Niu J, Ding W (2012) Comparison of biodegradable behaviors of AZ31 and $\mathrm{Mg}-$ $\mathrm{Nd}-\mathrm{Zn}-\mathrm{Zr}$ alloys in Hank's physiological solution. Mater Sci Eng B 177:395-401

[9] Abidin NIZ, Rolfe B, Owen H, Malisano J, Martin D, Hofstetter J, Uggowitzer PJ, Atrens A (2013) The in vivo and in vitro corrosion of high-purity magnesium and magnesium alloys WZ21 and AZ91. Corros Sci 75:354-366

[10] Han H, Minghui Y, Seok H, Byun J, Cha P, Yang S, Kim YC (2013) The modification of microstructure to improve the biodegradation and mechanical properties of a biodegradable Mg alloy. J Mech Behav Biomed Mater 20:54-60

[11] op't Hoog C, Birbilis N, Estrin Y (2008) Corrosion of pure $\mathrm{Mg}$ as a function of grain size and processing route. Adv Eng Mater 10:579-582

[12] Huang Y, Figueiredo RB, Baudin T, Langdon TG (2012) Evolution of strength and homogeneity in a magnesium AZ31 alloy processed by high-pressure torsion at different temperatures. Adv Eng Mater 14:1018-1026

[13] Kawasaki M, Figueiredo RB, Huang Y, Langdon TG (2014) Interpretation of hardness evolution in metals processed by high-pressure torsion. J Mater Sci 49:6586-6596. https://doi. org/10.1007/s10853-014-8262-8

[14] Lee H, Ahn B, Kawasaki M, Langdon TG (2015) Evolution in hardness and microstructure of ZK60A magnesium alloy processed by high-pressure torsion. J Mater Res Technol 4:18-25

[15] Edalati K, Yamamoto A, Horita Z, Ishihara T (2011) Highpressure torsion of pure magnesium: evolution of mechanical properties, microstructures and hydrogen storage capacity with equivalent strain. Scripta Mater 64:880-883

[16] Figueiredo RB, Cetlin PR, Langdon TG (2011) Using finite element modeling to examine the flow processes in quasiconstrained high-pressure torsion. Mater Sci Eng A 528:8198-8204

[17] Figueiredo RB, Pereira PHR, Aguilar MTP, Cetlin PR, Langdon TG (2012) Using finite element modeling to examine the temperature distribution in quasi-constrained high-pressure torsion. Acta Mater 60:3190-3198

[18] Edalati K, Horita Z, Langdon TG (2009) The significance of slippage in processing by high-pressure torsion. Scripta Mater 60:9-12

[19] Loucif A, Figueiredo RB, Kawasaki M, Langdon TG (2012) Effect of aging on microstructural development in an Al$\mathrm{Mg}-\mathrm{Si}$ alloy processed by high-pressure torsion. J Mater Sci 47:7815-7820. https://doi.org/10.1007/s10853-012-6400-8

[20] Bonarski BJ, Schafler E, Mingler B, Skrotzki W, Mikulowski B, Zehetbauer MJ (2008) Texture evolution of Mg during high-pressure torsion. J Mater Sci 43:7513-7518. https://doi.org/10.1007/s10853-008-2794-8

[21] Čížek J, Procházka I, Smola B, Stulíková I, Kužel R, Matěj Z, Cherkaska V, Islamgaliev RK, Kulyasova O (2007) Microstructure and thermal stability of ultra fine grained Mgbased alloys prepared by high-pressure torsion. Mater Sci Eng A 462:121-126

[22] Kawasaki M, Figueiredo RB, Langdon TG (2011) An investigation of hardness homogeneity throughout disks processed by high-pressure torsion. Acta Mater 59:308-316

[23] Figueiredo RB, Aguilar MTP, Cetlin PR, Langdon TG (2011) Deformation heterogeneity on the cross-sectional planes of a magnesium alloy processed by high-pressure torsion. Metall Mater Trans A 42A:3013-3021

[24] Al-Zubaydi A, Figueiredo RB, Huang Y, Langdon TG (2013) Structural and hardness inhomogeneities in $\mathrm{Mg}-\mathrm{Al}-$ $\mathrm{Zn}$ alloys processed by high-pressure torsion. J Mater Sci 48:4661-4670. https://doi.org/10.1007/s10853-013-7176-1

[25] Qiao XG, Zhao YW, Gan WM, Chen Y, Wu K, Gao M, Starink MJ (2014) Hardening mechanism of commercially pure $\mathrm{Mg}$ processed by high pressure torsion at room temperature. Mater Sci Eng A 619:95-106

[26] Ahmadkhaniha D, Järvenpää A, Jaskari M, Sohi MH, ZareiHanzaki A, Fedel M, Deflorian F, Karjalainen LP (2016) Microstructural modification of pure $\mathrm{Mg}$ for improving mechanical and biocorrosion properties. J Mech Behav Biomed Mater 61:360-370

[27] Kawasaki M (2014) Different models of hardness evolution in ultrafine-grained materials processed by high-pressure torsion. J Mater Sci 49:18-34. https://doi.org/10.1007/ s10853-013-7687-9

[28] Huang Y, Figueiredo RB, Baudin T, Helbert AL, Brisset F, Langdon TG (2013) Microstructure and texture evolution in a magnesium alloy during processing by high-pressure torsion. Mater Res 16:577-585

[29] Valiev RZ, Alexandrov IV, Zhu YT, Lowe TC (2002) Paradox of strength and ductility in metals processed by severe plastic deformation. J Mater Res 17:5-8

[30] Biswas S, Dhinwal SS, Suwas S (2010) Room-temperature equal channel angular extrusion of pure magnesium. Acta Mater 58:3247-3261

[31] Song GL, Xu Z (2012) Effect of microstructure evolution on corrosion of different crystal surfaces of AZ31 Mg alloy in a chloride containing solution. Corros Sci 54:97-105

[32] Ascencio M, Pekguleryuz M, Omanovic S (2014) An investigation of the corrosion mechanisms of WE43 Mg alloy in a modified simulated body fluid solution: the influence of immersion time. Corros Sci 87:489-503

[33] Yamashita A, Horita Z, Langdon TG (2001) Improving the mechanical properties of magnesium and a magnesium alloy 
through severe plastic deformation. Mater Sci Eng A 300:142-147

[34] Figueiredo RB, Cetlin PR, Langdon TG (2007) The processing of difficult-to-work alloys by ECAP with an emphasis on magnesium alloys. Acta Mater 55:4769-4779

[35] Cetlin PR, Aguilar MTP, Figueiredo RB, Langdon TG (2010) Avoiding cracks and inhomogeneities in billets processed by ECAP. J Mater Sci 45:4561-4570. https://doi.org/ 10.1007/s10853-010-4384-9

[36] Horita Z, Matsubara K, Makii K, Langdon TG (2002) A two-step processing route for achieving a superplastic forming capability in dilute magnesium alloys. Scripta Mater 47:255-260

[37] Lee HJ, Lee SK, Jung KH, Lee GA, Ahn B, Kawasaki M, Langdon TG (2015) Evolution of hardness and texture of a ZK60A magnesium alloy processed by high-pressure torsion. Mater Sci Eng A 630:90-98

[38] Torbati-Sarraf SA, Sabbaghianrad S, Figueiredo RB, Langdon TG (2017) Orientation imaging microscopy and microhardness in a ZK60 magnesium alloy processed by high-pressure torsion. J Alloys Compd 712:185-193

[39] Sabbaghianrad S, Torbati-Sarraf SA, Langdon TG (2018) An investigation of the limits of grain refinement after processing by a combination of severe plastic deformation techniques: a comparison of $\mathrm{Al}$ and $\mathrm{Mg}$ alloys. Mater Sci Eng A 712:373-379

[40] Silva CLP, Oliveira AC, Costa CGF, Figueiredo RB, MdeF Leite, Pereira MM, Lins VFC, Langdon TG (2017) Effect of severe plastic deformation on the biocompatibility and corrosion rate of pure magnesium. J Mater Sci 52:5992-6003. https://doi.org/10.1007/s10853-017-0835-X

[41] Xin R, Luo Y, Zuo A, Gao J, Liu Q (2012) Texture effect on corrosion behavior of AZ31 Mg alloy in simulated physiological environment. Mater Lett 72:1-4

[42] Nie M, Wang CT, Qu M, Gao N, Wharton JA, Langdon TG (2014) The corrosion behavior of commercial purity titanium processed by high-pressure torsion. J Mater Sci 49:2824-2831. https://doi.org/10.1007/s10853-013-7988-z 